\title{
PERAN PEKERJA SOSIAL DALAM PELAYANAN PALIATIF (STUDI KASUS DI INSTALASI PALIATIF DAN BEBAS NYERI RSUD DR. SOETOMO SURABAYA)
}

\author{
Pairan \\ Ilmu Kesejahteraan Sosial, Fakultas Ilmu Sosial dan Ilmu Politik, Universitas Jember, \\ Pairan.fisip@unej.ac.id \\ Misnia Septa Andiana \\ Ilmu Kesejahteraan Sosial, Fakultas Ilmu Sosial dan Ilmu Politik, Universitas Jember, \\ Niaseptaandiana99.ns@gmail.com
}

\begin{abstract}
Indonesia is currently experiencing a parallel epidemiological transition, the epidemiological transition can be marked by a change in the pattern of death which is dominated by noncommunicable diseases. To overcome this phenomenon, palliative care is needed by the hospital. Palliative care is interdisciplinary and multi-professional care. One of the professions required in palliative service is the profession of social work. This is in appropriate with the Decree of the Minister of Health of the Republic of Indonesia No.812 / Menkes / SK / VII / 2007. Palliative service consists of service stages, namely administrative, medical and non-medical services. Administrative services are handled by the hospital administration department, medical services are carried out by the medical team, while nonmedical services are handled by psychologists, volunteers and social workers. This study has a purpose to describe the role of social workers in palliative services. This research use desciptive qualitative approach. In determining the location using the purposive area technique and the determination of informants using purposive sampling technique. Data collection was carried out by interview, observation and documentation. The data analysis technique was performed using the Miles and Huberman model which was carried out through data accumulate, data reduction, conclusions and verification. The results showed that the role of social workers needed in palliative services is the role of providing social support to patients and their families, helping patients and families to overcome financial problems, and playing a role in restoring social functioning of patients. The role in providing social support can be seen from how social workers also assist patients and their families and provide awareness of the importance of family roles for patients. The role in overcoming economic problems is to become a broker between patients and funding aid agencies. The role in restoring the patient's function is by providing motivation, understanding, and strengthening to the patient that he is valuable and very meaningful to his family and providing knowledge to the patient's family so that he continues to provide opportunities for patients to play a role socially according to the patient's condition.
\end{abstract}

Keywords:

Palliative Care, Role of Social Workers, Social functioning, Social Support, Economic support

\begin{abstract}
Abstrak
Indonesia saat ini mengalami transisi epidemiologi pararel, hal ini dapat dilihat dari berubahnya angka kematian yang didominasi oleh penyakit non infeksi atau penyakit yang tidak menular, untuk mengatasi fenomena tersebut, maka dibutuhkan perawatan paliatif yang dilakukan oleh rumah sakit. Perawatan paliatif merupakan perawatan yang interdisipliner dan multiprofesi. Salah satu profesi yang diperlukan dalam pelayanan paliatif adalah profesi pekerjaan sosial. Hal ini sesuai dengan Keputusan Menteri Kesehatan Republik Indonesia No.812/Menkes/SK/VII/2007. Dalam pelayanan paliatif terdiri dari tahapan-tahapan pelayanan, yaitu tahapan administratif, pelayanan medis, dan pelayanan non medis. Pelayanan administrasi ditangani oleh bagian adminsitrasi rumah sakit, pelayanan medis dilakukan oleh tim medis, sedangkan pelayanan non medis ditangani oleh psikolog, relawan dan pekerja sosial. Penelitian memiliki tujuan untuk mendiskripsikan peran peksos dalam perawatan paliatif. Pendekatan yang dipilih yaitu deskriptif kualitatif. Penentuan lokasi menggunakan
\end{abstract}


teknik purposive area dan penentuan informan menggunakan teknik purposive sampling. Pengumpulan data dilakukan dengan observasi, wawancara dan dokumentasi. Teknik analisis data menggunakan model Miles dan Huberman yang dilakukan melalui pengumpulan data, reduksi data, dan penarikan kesimpulan dan verifikasi. Hasil penelitian menggambarkan bahwa peran pekerja sosial yang dibutuhkan dalam pelayanan paliatif yaitu peran dalam memberikan social support kepada pasien dan keluarganya, berperan membantu pasien dan keluarganya dalam mengatasi masalah ekonomi, serta berperan dalam mengembalikan keberfungsian sosial pasien. Peran dalam memberikan social support dapat dilihat dari bagaimana pekerja sosial juga turut mendampingi pasien dan keluarga pasien serta memberikan penyadaran akan pentingnya peran keluarga bagi pasien. Peran dalam mengatasi masalah finansial yaitu dengan menjadi broker antara pasien dan lembaga pemberi bantuan dana. Peran dalam pengembalian keberfungsian pasien yaitu dengan memberikan motivasi, pengertian, dan penguatan kepada pasien bahwa dirinya berharga dan sangat bermakna bagi keluarganya serta memberikan pengetahuan kepada keluarga pasien agar tetap memberikan kesempatan kepada pasien untuk berperan secara sosial sesuai dengan kondisi pasien.

\section{Kata Kunci:}

Perawatan Paliatif, Peran Pekerja Sosial, Keberfungsian sosial, Dukungan Sosial, Dukungan ekonomi

\section{PENDAHULUAN}

Peningkatan pasien dengan penyakit terminal atau paliatif terus terjadi. World Health Organization (2007) menggambarkan bahwa diantara 29 miliar kasus dalam lingkup paliatif, 20,4 miliar kasus diantaranya membutuhkan pelayanan paliatif. Ditambah lagi dengan data yang menunjukkan bahwa Indonesia merupakan salah satu negara dengan angka prevalensi kanker dan HIV/AIDS yang terbilang tinggi dan terus mengalami peningkatan kasus dari 10,36\% (2006) menjadi 22,86\% (2014).

Penyakit kronis tersebut diantaranya yaitu penyakit degeneratif, kanker, penyakit paru obstruktif kronis, stroke, cystic fibrosis, gagal jantung, dan HIV/AIDS. Penyakit kronis memerlukan pelayanan paliatif, karena pelayanan ini memberikan pelayanan yang lebih holistik dimulai dari promotif, preventif, kuratif, dan rehabilitatif (Keputusan Menteri Kesehatan RI Nomor: 812/Menkes/SK/VII/2007).

Indonesia saat ini mengalami transisi epidemiologi pararel, hal ini dapat dilihat dari berubahnya angka kematian yang didominasi oleh penyakit non infeksi atau penyakit yang tidak menular (Pusdatin Kemenkes, 2012:1). Penyebab kematian dari penyakit tidak menular (PTM) pada kasus pasien yang berusia sebelum usia 60 tahun meliputi: penyakit kardiovaskular (39\%), kanker (27\%), penyakit pernafasan kronis, penyakit pencernaan dan penyakit tidak menular yang lain menyebabkan kurang lebih $30 \%$ kematian, dan selanjutnya $4 \%$ kematian disebabkan diabetes melitus.

Fenomena peningkatan epidemiologi pararel ini menjadi alasan mendasar bahwa pelayanan paliatif sangat diperlukan di rumah sakit. Berdasarkan pada Keputusan Menteri Kesehatan RI Nomor: 812/Menkes/SK/VII/2007, Rumah sakit yang memberikan pelayanan paliatif di Indonesia diantaranya Surabaya, Jakarta, Yogyakarta, Makassar dan Denpasar.

Provinsi Jawa Timur melalui RSUD Dr. Soetomo Surabaya membangun jejaring dengan rumah sakit lain diantaranya RSUD Saiful Anwar Malang, RSUD Soedono Madiun, RSUD Dr. Iskak Tulungangung, RSUD Sidoarjo, RSUD 
Ibnu Sina Gresik, RSUD Paru Jember, dan RSUD Jombang, dan beberapa rumah sakit swasta seperti RS Katolik Vincentius A Paulo Surabaya (RKZ) dan RS Baptis Batu untuk memberikan pelayanan paliatif di rumah sakit yang dikelola (Yayasan Paliatif Surabaya, 2019).

Konsep perawatan paliatif lebih menekankan pada adanya integrasi dari perawatan sejak awal diagnosis agar permasalahan fisik, psikologis, sosial, kultural dan spiritual dapat diatasi dengan maksimal. Hal ini dikarenakan yang dilayani dalam perawatan paliatif adalah pasien dengan penyakit terminal (kronis).

Menurut Woodruff (2003:8) pasien dengan penyakit terminal adalah pasien yang mengalami beberapa penderitaan (total suffering), yang merupakan penjelasan dari rasa sakit yang ditambah dengan gejala fisik (physical symtoms), masalah psikologis (psychological problems), kesulitan sosial (social difficulties), faktor kultural (cultural factors) dan spiritual (spiritual concern).

Total suffering merupakan penderitaan yang kompleks sehingga memerlukan pengobatan dengan pendekatan holistik. Pendekatan holistik dalam pelayanan paliatif mengintegrasikan berbagai pelayanan yang dilakukan oleh berbagai profesi, yaitu tenaga kesehatan, rihaniawan, keluarga, relawan dan pekerja sosial.

Huljev et.al (66: 2016) menjelaskan pengobatan holistik berarti pertimbangan manusia secara utuh baik fisik, psikologis, sosial, dan spiritual, pada manajemen dan pencegahan penyakit. Mereka harus dikelola bersama agar seseorang diperlakukan secara utuh. Prinsip pendekatan holistik meliputi: (1) Semua orang memiliki kekuatan penyembuhan bawaan; (2) Pasien adalah manusia, bukan tentang hanya penyakit; (3) Perawatan penyembuhan yang tepat membutuhkan pendekatan tim; (4) Pasien dan dokter adalah mitra dalam proses penyembuhan; (5) Penanganan meliputi perbaikan penyebab penyakitnya, tidak hanya mengobati gejalanya.

Terkait dengan pelayanan paliatif Shavitri (2020) menjelaskan perawatan paliatif semakin besar dibutuhkan pada pasien kanker, dan penyakit non-kanker. Sebagaian besar kebutuhan palliative care untuk penyakit kronik, beberapa diantaranya yaitu penyakit kardiovaskular, kanker, penyakit paru obstruktif kronik, diabetes melitus, HIV/AIDS, penyakit ginjal kronik, artritis rematik, penyakit hati kronik, penyakit neurologis, anomali kongenital, demensia, dan tuberkulosis resisten obat.

Peran pekerja sosial dalam pelayanan paliatif dilakukan berdasarkan pendekatan biospsychosocialculturospiritual, dengan tujuan agar tidak ada satu masalah yang tidak dilayani atau diobati yang merupakan salah satu akibat penderitaan. Pendekatan biospsychosocialculturospiritual merupakan pendekatan yang lebih kompleks dan holistik.

Berdasarkan pendekatan pelayanan paliatif yang holistik, maka pekerja sosial mempunyai peran strategis untuk menguatkan pelayan paliatif pada aspek psikologi, sosial dan kultural. Sehingga penting utnuk diketahui peran apa saja yang dibutuhkan dalam pelayanan paliatif.

\section{METODE}

Pendekatan dari penelitian ini adalah deskriptif kualitatif yang berfokus untuk meneiliti tentang peran pekerja 
sosial yang diperlukan dalam pelayanan paliatif di rumah sakit. Lokasi penelitian ini berada di Instalasi Palaitif dan Bebas Nyeri RSUD Dr. Soetomo Surabaya. Informan pokok dari penelitian ini adalah dokter pelayanan paliatif dan pekerja sosial. Pengumpulan data dilakukan menggunakan teknik observasi, wawancara, dan dokumentasi. Analisis data penelitian menggunakan model analisis terpadu mulai dari pengumpulan data, reduksi data, penarikan kesimpulan dan verifikasi. Validasi dilakukan melalui teknik triangulasi sumber.

\section{HASIL PENELITIAN}

Tahapan pelayanan paliatif di RSUD Dr. Soetomo Surabaya dimulai dari kedatangan pasien ke Instalasi Paliatif dan Bebas Nyeri. Pada proses ini, pasien akan menyelesaikan persyaratan administratif. Pekerja sosial berperan dalam membantu pasien dalam menyelesaikan persyaratan administratif dengan memeriksa berkas-berkas pendukung dan meneruskan ke bagian pendaftaran. Peran ini juga dapat disebut sebagai broker. Berkas yang harus diperiksa sesuai dengan ketentuan yang ditetapkan di instalasi paliatif. Hal ini sejalan dengan apa yang disampaiakan informan PL:

"Di intalasi paliatif, jika ada yang bermasalah secara sosial saya yang membantu. Bisa ke sini, bisa ke sini.

Contohnya kemarin ada yang membutuhkan kaki palsu, saya yang menguruskan. Lebih tepatnya membantu keluarganya untuk menguruskan. Mereka akan saya antar ke bagian administrasi, saya hubungkan dan mengantarkan. Jika diperlukan ya saya ke tempat lain. Jika ada pasien yang kesini sendiri tanpa keluarganya, saya yang menagmbilkan JKN ke rawat jalan. Tapi untuk mereka yang benar-benar tidak ada keluarganya yang mengantar. Soalnya pasien-pasien yang dari rumah singgah biasanya ada relawan yang nganter dan mengambilkan.

Relawan tersebut dari luar..."

Tahapan selanjutnya yaitu pelayanan medis. Pekerja sosial berperan membantu dalam proses pra pelayanan medis. Setelah pasien menyelesaiakan persyaratan administratif, tahap selanjutnya yaitu pasien akan menuju dokter penanggung jawab masing-masing pasien. Pekerja sosial dalam tahap ini berperan mengantar pasien kepada dokter yang di tuju, diawali dengan pengecekan berkas-berkas administrasi dan rujukan pasien. Hal ini bertujuan agar pasien mendapatkan pelayanan dari dokter sesuai dengan penyakitnya. Sebagaimana disampaikan oleh informan PL:

"Setelah pasien selesai dengan urusan administrasi, kemudian dari ruang perawat saya yang naikkan pasien ke dokter yang di tuju. Sebelum mengantar saya akan selalu melihat berkas-berkas pasien. Saya memastikan pasien ditangani sesuai dengan data pada berkas..." (Informan PL, 27 Juni 2020).

Hal ini juga diperkuat dengan penjelasan informan WIM:

"Pada tahap awal, pekerja sosial akan mendampingi pasien dalam proses administratif, setelah itu pekerja sosial dan membantu perawat dengan mengantarkan pasien ke dokter yang dituju sesuai alur dan kebutuhan pasien..." (Informan WIM, 4 Agustus 2020).

Pernyataan di atas menunjukkan bahwa peran pekerja sosial sangat dibutuhkan di instalasi paliatif bahkan sejak awal pasien masuk ke instalasi paliatif. Pekerja sosial juga turut membantu perawat dalam hal sterilisasi 
peralatan medis, rawat luka, dan sebagainya. Namun tentunya didampingi oleh tim medis dan telah mendapatkan persetujuan dari dokter. Sebagaimana dijelaskan oleh informan PL:

“...saya juga melakukan tugas sebagai pekarya kesehatan, tugasnya untuk membantu perawat untuk melakukan sterilisasi peralatan medis, menyiapkan peralatan medis, membantu melakukan rawat luka, serta memberi edukasi kepada pasien dan keluarganya tentang bagaimana cara melakukan rawat luka pada pasien. Namun tentu saja tetap didampingi oleh dokter maupun perawat" (Informan PL, 27 Juni 2020).

Pekerja sosial sangat dibutuhkan dalam pelayanan paliatif. Hal ini dikarenakan tidak semua aspek dapat ditangani oleh dokter dan tim medis. Setiap profesi memiliki batasan profesional yang memang harus dijaga, sehingga interdependensi antar profesi memang dibutuhkan dan setiap profesi tidak akan mengalami kesalahan dalam pengambilan keputusan.

Pekerja sosial tidak hanya berfokus kepada pasien, namun juga turut memberikan pelayanan kepada keluarga pasien. Pekerja sosial berperan untuk mengantisipassi, mencegah, sekaligus mengobati pasien dan keluarganya. Informan AAF menjelaskan bahwa:

"Jadi fokusnya di paliatif itu pasien dan keluarga. Karena di paliatif itu kalau pasiennya sakit satu keluarga ikut sakit. Itu pentingnya social worker itu di situ. Untuk mengantisipasi, mencegah sekaligus mengobati. Supaya tidak salah decission makernya. Itu pentingnya harus ada konseling itu tadi. Jadi bisa mengenai semua level. Cuman yang paling butuh bantuan kan level bawah. Itu pentingnya penjelasan, edukasi dan motivasi. Nyeri saja tidak hanya dari fisik, total pain. Tapi di paliatif itu total suffering. Jadi keluhan A-Z itu ada di paliatif.
Jadi pekerja sosial itu sangat dibutuhkan di paliatif itu. Karena dokternya tidak mungkin bisa menghandle, yang bisa hanya secara umum. Tapi lebih detail tindak lanjut dan solusinya itu di pekerja sosial medis yang tahu persis" (Informan AAF, 5 Agustus 2020).

\section{Peran dalam Memberikan Dukungan Sosial Pasien Paliatif}

Setelah menerima pelayanan medis, dokter akan melakukan asesmen secara singkat terhadap pasien. Ketika pasien dirasa perlu mendapat pelayanan non medis di instalasi paliatif, maka dokter akan memberikan rekomendasi kepada pekerja sosial. Rekomendasi tersebut seperti pasien diharuskan rawat luka yang dapat dilakukan di ruang day care, pemberian layanan kejiwaan, dan pemberian layanan oleh pekerja sosial medis. Sebagaimana dijelaskan oleh informan WIM:

"Pekerja Sosial Medis melaksanakan tugas yang diberikan oleh dokter. Menindaklanjuti dalam hal kepentingankepentingan pasien dalam bidang sosial medis. Tapi harus sesuai dengan instruksi dari dokternya. Jadi tidak boleh bertindak atas kemauannya sendiri. Seperti Bu Puji kan batasan dia tidak boleh melebihi dari wewenang yang kita berikan..." (Informan WIM, 4 Agustus 2020).

Jika pasien direkomendasikan untuk mendapat pelayanan pekerja sosial medis, maka pekerja sosial medis memiliki peran untuk melakukan asesmen pada aspek fisik, psikis, sosial, kultural dan spiritual. Sebagaimana dijelaskan oleh informan WIM:

"Bagi saya, untuk melengkapi dan sebagai kepanjangan tangan kita. Karena kembali lagi memberikan pelayanan harus paripurna, service excellent, ya sangat penting 
keberadaan pekerja sosial medis. Paliatif itu bukan hanya tentang biopsychosocial saja, namun juga menyangkut kultural dan spiritual. Ketika pasien sakit pelayanan yang kita berikan juga harus memperhatikan latar belakang kulturalnya. Cara penyampaian, gaya bicara, pendekatan-pendekatan di untuk setiap kultur yang berbeda juga akan berbeda. Kemudian ketika sakit apakah pasien hanya terganggu fungsi sosialnya? Tidak. Pasien juga akan terganggu dalam aspek spiritualnya. Spiritual itu tidak hanya tentang agama, namun agama di dalamnya. Spiritual termasuk juga integritas pasien, dan lain sebagainya. Ini harus diperhatikan dalam pelayanan paliatif" (Informan WIM, 4 Agustus 2020).

Hal ini dikuatkan pula oleh pendapat informan AAF:

"Peksos Medis itu penting di Paliatif terutama karena pasiennya banyak pasien kanker stadium lanjut. Tapi sebetulnya paliatif itu bukan hanya untuk kanker. Sehingga HIV/AIDS juga ada tapi sebagian besar kanker yang sudah stadium lanjut. Pendekatan pasien dengan kanker itu otomatis banyak penderitaannya tidak hanya fisik, psikologi, sosial, kultural dan spiritual. Karena nomor satu di paliatif itu pengobatannya dan pendekatannya harus holistik. Jadi melihat seseorang tidak bisa hanya fisik saja tapi semua aspek harus dilihat" (Informan AAF, 5 Agustus 2020)

Aspek-aspek yang digali oleh pekerja sosial medis tidak jauh berbeda dengan aspek yang disebutkan sebelumnya, bahwa assesmen dilakukan dengan wawancara maupun dengan menggunakan kuisioner atau Formulir Laporan Pekerja Sosial Medis yang berisi identitas pasien; data keluarga pasien; keadaan dan aktivitas penderita; tanggapan penderita terhadap penyakit dan masa depannya; tanggapan keluarga terhadap penderita; tanggapan masyarakat terhadap penderita; sosial ekonomi keluarga penderita; keadaan tempat tinggal dan lingkungan penderita; kesimpulan penderita; rencana kerja Pekerja Sosial Medis. Asesmen dilakukan dengan tekik wawancara dan digabungkan dengan pengisisn formulir. Sebagaiamana dijelaskan oleh Informan PL:

Ketika Bed Consul, akan ada status yang diisi dari saya. Isinya tidak jauh beda dengan status yang dibagikan oleh perawat. Isinya terkait pertanyaanpertanyaan untuk menggali keadaan sosial ekonomi pasien. Kemudiaan ada aspek spiritual dan kultural yang turut ditanyakan. Kalau kultural ditanyakan dari awal sakit berobatnya kemana saja. Ada yang langsung ke dokter, ada yang langsung ke puskesmas, kita tanyakan juga apa pernah ke alternatif. Alternatif kan macam-macam ada yang obat herbal, dll. Spiritual selama sakit itu pasiennya apakah masih bisa beribadah atau tidak, masih bisa ikut kegiatan keagamaan atau tidak. Pasien kita arahkan untuk tetap menjalankan ibadah. Jika pasien tidak mampu, keluarga kita arahkan untuk menemani di sebelahnya, diajari cara tayamum dan lain-lain. Fungsi dari status ini nanti jika ada yang menanyakan, seperti dokter atau perawat. Hasilnya nanti akan menjadi pertimbangan bagi dokter untuk memberikan tindakan selanjutnya pada aspek sosial medisnya" (Informan PL, 27 Juni 2020)

Setelah asesmen pekerja sosial memberikan pelayanan kepada pasien dengan mencoba menenagkan dan mulai membangun penerimaan kepada pasien dan keluarganya. Karena pada dasarnya pasien dan keluarganya datang dengan kondisi psikologis yang lemah. Pekerja 
sosial mencoba menenangkan dan mulai membangun penerimaan kepada pasien dan keluarga pasien. Pekerja sosial juga selalu berhati-hati dalam melakukan pendekatan. Karena pada dasarnya tujuan dari pelayanan paliatif adalah memberdayakan. Pekerja sosial juga memberikan social and emotional support. Sebagaimana dijelaskan oleh informan PL:

“...Kendala lain lagi biasanya kebanyakan keluarganya tidak bisa menerima tentang penyakitnya. Pasiennya sendiri juga beberapa dari mereka kurang bisa menerima. Cara pendekatannya juga harus diperhatikan. Karena sebagian dari mereka salah mengartikannya. Kadang ketika kita mambantu dikira kita akan membantu terus-terusan. Khususnya soal finansial. Kita memang membantu di bidang itu untuk menghubungkan ke pihakpihak yang bisa membantu. Namun poin utama kita kan membantu agar dia bisa menerima sakitnya, keluarga dan lingkungan bisa menerima keadaanya. Bantuan tersebut berupa dukungan emosional dan sosial. Saya menekankan bahwa segala penyakit pasti ada obatnya" (Informan PL, 27 Juni 2020).

Dalam melakukan intervensi, pekerja sosial medis juga berperan dalam memberikan social support kepada pasien dan keluarga pasien, Karena pada dasarnya pasien juga tidak mudah untuk dapat menerima kondisi sakitnya. Sehingga pekerja sosial juga turut mendampingi pasien dan keluarga pasien. Tujuan dari pendampingan adalah agar pasien dapat menerima keberadaan dirinya yang sakit dan menyadari bahwa masih ada orang-orang di sekitar yang mendukungnya. Bagi keluarga pasien, penyadaran bahwa keluarga memiliki fungsi penting dalam mengakselerasi kesembuhan pasien adalah yang utama. Sebagaimana dijelaskan oleh Informan PL: "Pasien itu berada dalam masa-masa yang sangat rentang, begitu juga keluarganya. Terkadang pasien masih bergelut dengan batinnya. Agar dapat menerima penyakitnya. Saya sebagai peksos tentu menguatkan.
Memberikan support sosial kepada pasien. Tujuannya agar pasien tidak merasa sendiri. Agar keluarga mau mendampingi pasien. Dan semua penyakit ada obatnya" (Informan PL, 27 Juni 2020)

\section{Peran dalam Memberikan Dukungan Finansial Pasien Paliatif}

Pekerja sosial berperan membantu pasien dan keluarga dalam mengatasi kesulitan finansial. Pekerja sosial medis berperan sebagai broker dan advocator untuk dapat membantu permasalahan finansial pasien.

Saat permasalah ditemukan melalui asesmen, maka dokter akan memberikan rekomendasi kepada Pekerja Sosial Medis bahwa ada pasien yang membutuhkan bantuan secara finansial. Kemudian pekerja sosial medis akan menindaklanjuti dengan melakukan asesmen mendalam baik melalui kuisioner maupun wawancara dengan pasien. Berikut pernyataan Informan MS: “...Disarankan untuk banyak-banyak berdoa. Shalat karena kita sebagai orang islam. Tadi juga ditanya keadaan ekonomi saya. Jika memungkinkan katanya akan dibantu sebisa mungkin. Akan dihubungkan ke yayasan apa tadi saya lupa. Tapi masih dalam pertimbangan mbak. $Y a$ alhamdulillah mbak bisa sedikit ada harapan..." (Informan MS, 3 Agustus 2020).

Ketika pasien memang memenuhi syarat untuk mendapat bantuan finansial, pekerja sosial medis akan melaporkan kepada dokter dan pejabat terkait. Apabila dokter dan pejabat terkait menyetujui maka pekerja sosial medis akan menghubungkan pasien dengan sumbersumber yang memang memiliki kerjasama dengan Instalasi Paliatif dan Bebas Nyeri di RSUD Dr. Soetomo Surabaya. 
Untuk membantu mengatasi kesulitan finansial, pekerja sosial dapat menghubungkan dengan CSR (Coorporate Social Responsibility) yang sudah bekerja sama dengan rumah sakit. Sebagaimana dikemukakan oleh Informan AAF: “...Pekerja sosial wawasannya harus luas, harus bisa mengantisipasi karena problemnya luar biasa. Jadi kalau punya program, punya target ya harus punya networking dengan minimal CSRCSR itu. Jadi selama ini kita masih dari personil dokter-dokternya, atau dari bantuan mana. Tapi kalau bisa kerjasama dengan CSR kita memberikan data itu lebih bagus. Jadi PSM harus proaktif untuk selain profesional di bidangnya, paham dan pu nya kompetensi, tapi juga harus punya kreatifitas dan inovasi untuk bisa mencarikan solusi. Karena pasiennya rata-rata tidak kuat dan tidak mampu. Pasti goncang secara finansial. Didiagnoasa saja goncang apalagi pengobatan itu biayanya banyak. Kadangkala ada BPJS tapi tidak semua obat di cover, kedua untuk transportasi dan pengobatannya ratarata lama. Pasti berpengaruh, berat. Harusnya gotongroyong dengan CSR. Apalagi dengan kondisi covid seperti ini..." (Informan AAF, 5 Agustus 2020).

Selain CSR, lembaga lain yang dapat memberikan bantuan finansial dan dapat diakses oleh pasien dengan bantuan pekerja sosial adalah Dinas Kesehatan Kora, Yayasan Paliatif Surabaya dan donatur yang memang telah dikoordinasi sedemikian rupa oleh Instalasi Paliatif dan Bebas Nyeri di RSUD Dr. Soetomo Surabaya. Bantuanbantuan juga tidak hanya berupa bantuan finansial, ada relawan yang memberikan bantuan tenaga sebagai pendamping dan broker antara pasien dan Instalasi Paliatif dan Bebas Nyeri di RSUD Dr. Soetomo Surabaya.

Selain sumber finansial di atas, pekerja sosial juga bisa menghubungkan kepada beberapa komunitas yang memberikan bantuan alat kesehatan seperti masker dan face shield. Ada pula yang memberikan bantuan mobil yang digunakan untuk home care. Hal tersebut sesuai dengan pendapat Informan AAF: "Di sini ada yayasan, ada anak asuh di sini. Ada donatur ya, relawan membentuk bagian dana, namanya yayasan, yaitu salah satunya menyekolahkan anak-anak yang tidak bisa sekolah. Selain membantu beberapa obat-obatan yang tidak dicover

BPJS. Bu Puji yang nanti ikut menghubungkan antara yayasan dengan pasien. Yayasan Paliatif Surabaya, itu berdirinya dari relawan yang khusus untuk dana. Minatnya minat dana. Ada yang minat home care, spiritual, pendampingan pasien di poli. Lah yayasan itu minat dana, menghimpun dari perusahaanperusahaan. Itu ada

AD/ARTnya sendiri, salah satunya untuk mensupport obat-obatan untuk pasien paliatif maupun anak asuh. Kemudian biasanya ada donaturdonatur dari komunitas. Seperti TIMUNSEGAR, ibuibu muda sehat dan bugar. Mereka memberikan mobil untuk home care. Kemarin memberikan face shield dan masker. Terus ada donatur yang memberikan susu..." (Informan AAF, 5 Agustus 2020).

\section{Peran dalam Mengembalikan}

\section{Keberfungsian Sosial Pasien Paliatif}

Peran lain yang dilakukan oleh pekerja sosial dalam pelayanan paliatif adalah mengembalikan keberfungsian sosial pasien. Pasien dengan penyakit terminal tentu sangat terganggu aspek sosialnya. Hal ini terkait dengan kondisi pasien paliatif karena sebagian besar pasien paliatif mengalami ketidakberfungsian sosial dikarenakan penyakitnya, interaksi sosialnya terbatas, 
dan merasa tidak berharga (useless). Sehingga pekerja sosial berperan penting dalam pemberian motivasi, pengertian dan penguatan kepada pasien bahwa dirinya berharga dan sangat bermakna bagi keluarganya. Sebagaimana dijelaskan oleh informan PL:

"Kebanyakan pasien ingin diakui. Pasien igin dihargai sebagaimana dulu sebelum dia sakit. Sehingga saya sebagai pekerja sosial terus mengingatkan kepada keluarganya untuk tetap memberikan peran-peran yang dirasa masih mampu untuk dilakukan oleh pasien" (Informan PL, 27 Juni 2020).

Pekerja sosial memberikan pengetahuan kepada keluarga pasien agar tetap memberikan kesempatan kepada pasien untuk berperan secara sosial sesuai dengan kondisi pasien. Seperti tetap mengadakan acara perkumpulan rutin di rumah, tetap meminta pendapat dalam beberapa hal, agar pasien dapat merasa masih dihargai sebagai seorang individu.

"Saya selalu menanyakan ketika sehat bagaimana pasien berinteraksi secara sosial. Saya selalu menekankan agar kegiatan-kegiatannya yang dulu ketika memang masih bisa dilakukan pasien harus di dukung. Contohnya ketika pasien sering berkumpul dengan teman-temannya, maka undang temantemannya ke rumah. Tanyakan kepada pasien terkait keinginankeinginan sosialnya" (Informan PL, 27 Juni 2020).

Pekerja sosial juga memberikan pengetahuan kepada keluarga pasien tentang bagaimana cara mengembalikan fungsi sosial pasien melalui pemberian peran-peran sosial yang sederhana sesuai dengan kedudukan pasien di keluarga. Sehingga pasien akan tetap merasa dihargai sebagai individu yang memiliki peran dan fungsi sosial yang melekat. Ketika pasien adalah seorang ayah, maka pasien haruslah terus dilibatkan dalam diskusi-diskui terkait dengan fungsinya sebagai ayah. Namun tetap dalam koridor yang sesuai dengan kemampuan pasien dengan kondisinya yang baru. Keluarga juga diharuskan dapat tetap menghormati pasien layaknya sebelum dalam kondisi sakit.

Sebagaimana dijelaskan oleh informan PL:

"Sebagai contoh begini, pasien yang barusan adalah seorang ayah. Sehingga saya sampaikan kepada keluarganya agar tetap mengorangkan pasien. Dengan tetap bertanya kepada pasien terkait halhal yang memang membutuhkan masukan dari seorang ayah. Kemudian tetap menghormati pasien layaknya sebelum dia sakit. Hal-hal semacam itu yang terus saya tanamkan kepada keluarganya" (Informan PL, 27 Juni 2020).

\section{PEMBAHASAN}

Peran-peran pekerja sosial medis sangat dibutuhkan dalam pelayananpelayanan yang di Instalasi Paliatif dan Bebas Nyeri RSUD Dr. Soetomo Surabaya. Jenis-jenis pelayanan yang diberikan di instalasi ini adalah Home Care, Day Care, Respite Care, Rawat Inap dan Rawat Jalan. Berbagai jenis pelayanan tersebut didukung pula dengan interdiciplinary team. Sehingga Pekerja Sosial dalam menjalankan perannya berkolaborasi dengan disiplin lain diantaranya dengan Dokter dan Perawat. Hal ini sesuai dengan Perawatan Paliatif yang memiliki pendekatan yang holistik sehingga dalam pelaksanaannya membutuhkan pekerj sosial bekerja multidisciplinary approach and multidisciplinary team. Tim dalam perawatan paliatif berasal dari berbagai bidang profesi, hal ini ditujukan agar antar profesi saling melengkapi satu sama lain 
hingga terbentuk pelayanan yang holistik. Woodruff (10:1993) menjelaskan bahwa multidisciplinary team meliputi medical staff, nursing staff, social worker, physiotherapist, dietician, psychologist, psychiatrist, chaplain, other personel, as required, kemudian ditambah dengan keluarga dan relawan.

pekerja sosial medis, dan menurut Surat Keputusan Menteri Kesehatan RI No. 51/Menkes/SK/1179 RSUD Dr. Soetomo adalah rumah sakit yang telah ditetapkan sebagai Tipe A. Berdasarkan kewajiban tersebut, RSUD Dr. Soetomo Surabaya memiliki 1 orang pekerja sosial yang bertugas di Instalasi Paliatif dan Bebas Nyeri. Kebutuhan akan pekerja sosial medis di instalasi paliatif sangat jelas, sebagaimana dijelaskan dalam Keputusan Menteri Kesehatan Republik Indonesia Nomor 812/Menkes/SK/VII/2007 bahwa pelaksana perawatan paliatif adalah tenaga kesehatan, pekerja sosial, rohaniawan, keluarga, dan relawan.

Dalam praktik pekerja sosial medis terdapat lima jenis intervensi yang dilakukan oleh pekerja sosial medis adalah yaitu biopsychosocioculturospiritual. Untuk menjalankan kelima bentuk pelayanan paliatif yang dilakukan oleh pekerja sosial medis tersebut, proses diawali diawali dengan adanya rekomendasi dari dokter kepada pasien agar mendapat pelayanan dari pekerja sosial medis. Pekerja sosial medis tidak diperbolehkan bertindak tanpa berdiskusi terlebi dahulu dengan dokter. Hal ini dikarenakan jenis pasien yang dtangani di Instalasi Paliatif dan Bebas Nyeri RSUD Dr. Soetomo Surabaya merupakan pasien terminal, yaitu pasien kanker. Sebagaimana dikemukakan oleh White (2002) bahwa pasien dapat disebut memiliki penyakit terminal apabila pasien memiliki penyakit
Peran pekerja sosial medis di pelayanan paliatif memiliki dasar hukum yang jelas, yaitu Surat Keputusan Menteri Kesehatan Nomor 9873 Tahun 1992. Surat keputusan tersebut menjelaskan tentang kewajiban penyediaan Pekerja Sosial Medis di Rumah Sakit. Rumah sakit Tipe A berkewajiban memiliki jumlah 12 orang progresif (penyakit yang menuju ke arah kematian). Contohnya seperti penyakit kardiovaskular atau kanker, penyakit terminal ini dapat dikatakan harapan untuk hidup tipis, tidak ada lagi obat-obatan, tim medis sudah give up (menyerah) dan seperti yang di katakan di atas tadi penyakit terminal ini mengarah kearah kematian. (White, 2002).

Peran pekerja sosial medis yang dilakukan di RSUD Dr. Soetomo Surabaya mengkonfirmasi pendapat Altilio et. Al (2011) bahwa pentingnya pekerja sosial adalah karena perspektif, pengetahuan, dan keterampilan dari pekerja sosial yang unik, dilihat dari keahliannya dalam navigasi sistem medis dan sosial; dasar pengetahuan dalam memberikan dukungan, pendidikan, dan intervensi dengan pasien, keluarga, serta koordinasinya dalam tim, kemudian komitmennya terhadap keadilan sosial dan pengurangan kesenjangan di bidang kesehatan. Selain praktik langsung dengan pasien dan keluarga, peran pekerja sosial juga termasuk memberikan pendidikan bagi pasien, keluarga, komunitas, serta disiplin ilmu lainnya, serta advokasi untuk pasien di semua tingkat sistem.

Berdasarkan hal tersebut, pekerja sosial medis menjalankan peran sebagai educator dan advocator.

Peran-peran pekerja sosial yang dilakukan dalam pelayanan paliatif juga mengkonfirmasi pendapat Donna Reese 
dalam Altilio et. Al (2011) bahwa pekerja sosial adalah profesi paling berkualifikasi dalam menyelesaikan isu-isu pasien dan keluarganya dalam bidang:

- Konseling finansial

- Referrals

- Konseling tentang bunuh diri,denial, and kedukaan

- Menfasilitasi dukungan sosial

- Promoting cultural competence

- Providing community outreach - Crisis intervention

Peran pekerja sosial dalam meningkatkan keberfungsian sosial pasien paliatif mengkonfirmasi pendapat Adi dalam Angga (2009) bahwa pekerja sosial perlu memberikan dukungan kepada keluarga pasien agar bisa menciptakan interaksi sosial. Pekerja sosial medis memberikan masukan kepada keluarga pasien untuk terus dapat menciptakan interaksi sosial antara pasien dengan lingkungan sosialnya. Namun tetap dilakukan sesuai dengan keadaan pasien. Karena kesehatan pasien merupakan hal terpenting. Aspek-aspek lain hanyalah aspek yang diharapkan dapat mengakselserasi kesembuhan pasien.

Kondisi keberfungsian sosial yang ingin dicapai dalam pelayanan paliatif adalah menciptakan kemampuan seseorang, keluarga maupun keIompok untuk menjaIankan peran sosiaInya sesuai dengan harapan dari lingkungannya. Pemberian dukungan sosial kepada pasien dan keluarga merupakan peran kunci yang harus dilakukan oleh pekerja sosial medis. Sebagaimana dijelaskan oleh Pekerjaan sosial spesialis perawatan paliatif adalah profesi kunci untuk menyediakan dukungan individu dan sosial yang sangat dibutuhkan oleh orangorang yang menghadapi kehidupan yang dibatasi oleh penyakit-penyakit kronis (Peter et.al, 2007:13), tujuannya tentu untuk dapat mengakselerasi kesembuhan pasien dari aspek psikososial pasien.

Konsep dukungan sosial sendiri diartikan sebagai dukungan yang dapat mengurangi beban atau permasalahan yang dihadapi seseorang sehingga dapat dikatakan bahwa dukungan sosial merupakan model dukungan yang dihasilkan dari interaksi pribadi yang melibatkan salah satu atau lebih aspek emosi, penilaian, informasi, dan instrumen sehingga dapat mereduksi beban yang diterima individu (Santi, 2003). Berdasarkan penjelasan di atas, maka dukungan sosial merupakan dukungan yang sangat dibutuhkan oleh pasien. Karena dengan dukungan sosial, pasien dapat mengembangkan dirinya dan dapat merasakan semangat untuk melakukan pengobatan. Dukungan sosial juga dapat menguatkan pasien secara psikis. Pasien juga akan menjadi individu yang lebih optimis dalam melakukan pengobatan.

Hal ini sejalan dengan pendapat Yasmin (2015) bahwa dukungan sosiaI memiliki peranan yang penting dalam mencegah dari ancaman kesehatan mentaI. Individu yang memiliki dukungan sosial yang lebih kecil, lebih memungkinkan mengalami konsekuensi psikis negatif. Keuntungan individu yang memperoleh dukungan sosial yang tinggi akan menjadi individu lebih optimis daIam menghadapi kehidupan saat ini maupun masa yang akan datang.

Selain dukungan-dukungan di atas, pekerja sosial juga berperan memberikan dukungan ekonomi kepada pasien. Karena pada dasarnya pasien dengan kondisi terminal mengalami penderitaan total yang tentunya juga mempengaruhi aspek 
ekonominya. Sebagaimana dijelaskan Peter et.al, 2007: 165) melalui pekerjaan sosial, orang dapat memperoleh bantuan dalam memperbaiki kondisi-kondisi seperti peningkatan pendapatan, peningkatan materi sumber daya seperti akomodasi yang aman dan sesuai; praktis, dukungan interpersonal dan sosial; informasi, advokasi dan perantara dengan para profesional.

\section{KESIMPULAN}

Perawatan paliatif merupakan perawatan kesehatan yang bersifat holistik, menyangkut aspek fisik, psikis, sosial, kultural dan spiritual. Dalam mencapai perawatan yang holistik, perawatan paliatif membutuhkan tim multidisipliner yang terdiri dari berbagai profesi, salah satunya yaitu Pekerja Sosial Medis. Peran pekerja sosial diperlukan dalam setiap tahapan pelayanan paliatif. Tahapan pelayanan paliatif di RSUD Dr. Soetomo Surabaya terdiri dari pelayanan administratif, pelayanan medis dan pelayanan non medis. Peran pekerja sosial yang dibutuhkan dalam pelayanan paliatif yaitu peran dalam memberikan dukungan sosial kepada pasien dan keluarga, yang dilakukan melalui kegiatan pekerja sosial dalam mendampingi pasien dan keluarga pasien serta memberikan penyadaran akan pentingnya peran keluarga bagi pasien. Peran dalam mengatasi masalah finansial yaitu dengan menjadi broker antara pasien dan lembaga pemberi bantuan dana. Peran dalam pengembalian keberfungsian pasien yaitu dengan memberikan motivasi, pengertian, dan penguatan kepada pasien bahwa dirinya berharga dan sangat bermakna bagi keluarganya serta memberikan pengetahuan kepada keluarga pasien agar tetap memberikan kesempatan kepada pasien untuk berperan secara sosial sesuai dengan kondisi pasien.

\section{DAFTAR PUSTAKA}

Adi, Isbandi Rukminto.

(2005). Ilmu Kesejahteraan Sosial dan Pekerjaan Sosial, FISIP UI Press.

Angga, Y. 2009. Peran Pekerja Sosial Medis Dalam Pencapaian Kualitas Hidup Terbaik Bagi Pasien Dan Anggota Keluarga Pasien Kanker Stadium Lanjut Yang Menjalani Perawatan Paliatif Di Unit Layanan Paliatif Dan Kedokteran Komplementer Rumah Sakit Kanker "Dharmais". Fakultas Ilmu Sosial Dan Ilmu Politik Program Ilmu Kesejahteraan Sosial. Universitas Indonesia.

Altilio, T., S. Otis-Green. 2011. Oxford Textbook of Palliative Social Work. New York: Oxford University.

Huljev, D., T. Pandak. 2016. Holistic and team approach in health care. SIGNA VITAE. 11(2). 66-69.

Keputusan Menteri Kesehatan RI Nomor 812/MENKES/SK/VII/2007.Kebijakan

Perawatan Paliatif. 19 Juli 2007. Jakarta

Kementerian Kesehatan RI. 2012. Penyakit Tidak Menular. Jakarta : Pusat Data dan Informasi Kementerian Kesehatan RI.

Kementerian Kesehatan RI. 2012. Profil Kesehatan Indonesia tahun 2011. Jakarta : Pusat Data dan Informasi Kementerian Kesehatan RI.

Santi, D.Y. (2003). Hubungan Dukungan Sosial dengan Stres Kerja pada Pramuniaga. Skripsi.(tidak diterbitkan). Yogyakarta : Fakultas Psikologi Universitas Wangsa Manggala

Woodruff, R. 1993. Palliative Medicine. Victoria: Asperula Pty Ltd.

World Health Organization. 2007. Cancer Control Knowledge into Action 
Palliative Care. WHO Library

Cataloguing-in-Publication Data:

Switzerland.

Yayasan Paliatif Surabaya.

2019. https://paliatifsurabaya.com/.

Yasmin, L. 2015. Hubungan Antara

Dukungan Sosial Keluarga Dengan Konflik

Peran Ganda Pada Wanita Bekerja. Fakultas

Psikologi.Universitas Muhammadiyah

Surakarta 